\title{
CIVIC EDUCATION BERBASIS KEARIFAN LOKAL
}

\section{NGIMADUDIN}

STAI Bumi Silampari Lubuklinggau

ngimadudin@staibsllg.ac.id

\begin{tabular}{|c|c|}
\hline & Abstrak \\
\hline $\begin{array}{l}\text { Article History } \\
\text { Received : 03-07-2019 } \\
\text { Revised : 06-07-2019 } \\
\text { Accepted : 12-07-2019 } \\
\text { Keywords : } \\
\text { Civic } \\
\text { Education } \\
\text { Based On } \\
\text { Local Friends }\end{array}$ & $\begin{array}{l}\text { Caring for the nationality is managing this } \\
\text { unitary Republic of Indonesia to become } \\
\text { "gemah ripah loh jinawi toto tentrem } \\
\text { kertoraharjo". In Indonesian terminology is } \\
\text { a sentence which is an expression to } \\
\text { describe the condition of the Indonesian } \\
\text { motherland. Gemah ripah means jinawi } \\
\text { (abundant natural wealth) while toto } \\
\text { tentrem karto raharjo (peaceful state). Or } \\
\text { in the Arabic sense to be baldattun } \\
\text { toyyibatun wa robbun ghoffur. This } \\
\text { expression is not and mertajadi when the } \\
\text { management of the State deviates from the } \\
\text { importance of nation and state prosperity. } \\
\text { Local (local wisdom) wisdom becomes the } \\
\text { essence that must be able to be maintained } \\
\text { in the midst of the storm of global ideology } \\
\text { which ignores human values. When the } \\
\text { young generation begins to forget the } \\
\text { historical and cultural roots from which it } \\
\text { originated, then he will get lost in the } \\
\text { search for his true identity. }\end{array}$ \\
\hline
\end{tabular}

\section{Pendahuluan}

Pepatah kebangsaan yang berbunyi "bangsa yang besar senantiasa menjunjung tinggi dan menjaga nilai leluhurnya". Adalah sebuah pepatah dan petuah yang filosofinya mampu memberikan energi dan semangat, dan semangat tersebut sampai hari ini memberikan efek berdirinya bangsa ini. Para pendiri bangsa ini 
yakin, bahwa mereka juga belajar dari sejarah berdirinya kerajaankerajaan yang ada di Nusantara ini.

Transmisi pengetahuan sejarah mengenai fluktuasi berdirinya bangsa demikian melekat di dalam ranah pergolakan pemikiran para pendiri bangsa ini. Bangsa ini pernah getir dengan balutan perjuangan yang bersimbah darah, bangsa ini pernah getir karena lamanya penjajahan bercokol di tanah nusantara, dengan kurun waktu kurang lebih 350 tahun oleh pemerintah Belanda dan 3,5 tahun oleh Pemerintah Jepang. Setidaknya tujuh turunan rakyat, tidak bisa menikmati nikmatnya punya Negara sendiri.

Sebegitu getirnya perjuangan mereka dihadiahkan kepada kita, jangankan mengisi, memelihara hadiah mereka berupa "kemerdekaan" kita tidak amanah. Cetak biru "blue print" kemerdekaan di isi terus dengan pendangkalan identitas nasional, nasionalisme tergerus oleh kekuatan partisan sesaat, yang paling menyedihkan generasi muda kita ikut memilih "geng-geng kematian" sebagai wadah penyaluran hobi, ketimbang memikirkan nasib bangsa. Toh para elit dinegeri ini juga hobi mempertontonkan nilai-nilai yang memang tidak sesuai dengan prilaku dan identitas bangsa ini. Sekali lagi kita tidak amanah terhadap perjuangan para pendahulu kita, artinya transformasi ilmu tidak jalan dari "the founding fathers" kepada generasi hari ini.

Belajar dari Negara-negara maju, setidaknya ada dua pelajaran penting yang menjadi pelajaran bagi bangsa Indonesia, yakni pemerintahan yang bersih dan pendidikan yang maju ( clean governance dan good education). Bahkan sejarah membuktikan bahwa awal mula berdirinya pergerakan di Indonesia titik tekan utama adalah proses pendidikan. Adalah Soetomo seorang mahasiswa STOVIA - sekolah dokter jawa - di Batavia yang memimpin rapat pada tanggal 20 Mei 1908 pada minggu pagi, Soetomo memberikan sambutan bahwa begitu pentingnya proses pendidikan dan kebudayaan tersebut, terutama pendidikan terhadap hak-hak dan kewajiban warga Negara.

Dari kelompok rapat kecil yang diselenggarakan oleh mahasiswa pada saat itu, secara tidak sadar mengawali sebuah pergerakan kemerdekaan Indonesia. Hal itu dapat kita temukan dalam bukunya seorang sejarawan dari Cornell University Akira Nagazumi dengan buku yang berjudul “Bangkitnya Nasionalisme Indonesia” menggaris bawahi satu pernyataan dari perkumpulan mahasiswa 
dengan nama "Budi Oetomo" dalam surat edarannya berbunyi : "Kemajuan Bagi Hindia/Indonesia".

Identitas Indonesia itu adalah Pancasila, kelima sila itu diilhami dari nafas budaya asli Indonesia yaitu gotong royong. (Yudi Latif. 2011:19). Sikap-sikap kebersamaan yang terlukis dalam tata kehidupan bangsa Indonesia yang diajarkan oleh para leluhur harus tetap menjadi bagian yang tidak dapat dipisahkan oleh perubahan zaman sekalipun. Perubahan model idiologi jangan sampai merubah budaya asli Indonesia yang sudah tertanam begitu lama dan menjadi identitas bangsa. Budaya-budaya impor yang sangat gencar melalui isu globalisasi yang masuk ke Indonesia demikian deras, sehingga secara massif perubahan-perubahan pola pikir dan kelakuan dari pada masyarakat sedemikan cepat, selanjutnya berpengaruh terhadap budaya yang berkembang di tengah masyarakat.

Menoleh kebelakang dengan memperhatikan keotentikan sejarah perjalanan bangsa ini, sekarang kita sepantasnya merenung dan tergugah, ketika berbagai bangsa lain semakin kukuh mengibarkan identitas dirinya yang di kaitkan dengan berbagai macam produk teknologi unggulan ataupun Timnas dan Club Sepak Bola tingkat dunia, bangsa ini tengah di rundung malang, baik krisis politik, keuangan, pengangguran maupun tragedy bencana alam. Di saat lapisan elit saling bermanuver untuk membagi dan mempertahankan kekuasaan, dikalangan akar rumput demonstrasi dan pengedaran narkoba muncul di sana sini. Sejak dari pembunuhan, pemerkosaan, pengedaran narkoba, sampai VCD porno hampir setiap saat menghiasi sebagian media elektronik dan media massa kita. Massa mudah sekali marah dan main hakim sendiri gara-gara masalah sepele. Dalam kehidupan beragama, seseorang akan mudah sekali tersinggung dan mengancam kelompok lain yang dianggap berbeda pandangan.

Pendeknya, Indonesia hari ini yang oleh para orang tua dan guru selalu diceritakan sebagai Negara kaya raya, religius, dan ramah, atau dengan kata lain "gemah ripah loh jinawi..tata titi tentrem kerto raharjo” kini dikenal sebagai bangsa anarkis, pemarah dan korup.

\section{Kajian Teori}

Suatu Negara yang meniadakan keseimbangan antara pertumbuhan ekonomi dan tata nilai budaya sosisal yang berkembang pada bangsa itu maka akan terjadi apa yang dinamakan paradoksial 
kebangsaan, yaitu eksploitasi sumber daya alam yang menyebabkan malapetaka ekologi, kejahatan korporasi yang menyebar demikian luas, disintegrasi social dan kemungkinan akan terjadi perang. (Fritjof Capra, 1998:561)

Ketika lokalitas dan globalitas dapat disandingkan untuk saling menguatkan, maka nasionalisme harus dibangun sebagai suatu kesadaran bersama, pengalaman bersama, dimana NKRI sebagai Negara adalah perahunya, payungnya, sebagai panggung kehidupannya. Tanpa sedaran demikian, manusia Indonesia tanpa sadar merusak tempat hidupnya sendiri, melubangi perahunya sendiri, yang berakibat hilang di telan lautan, bahkan sampai musnah ditelan arus liar perkembangan zaman. (Jazim dan Mustafa, 2010:177)

Budaya sebagai kekuatan sejarah juga lebih awet daripada Negara, lebih masuk kedalam kesadaran kolektif masyarakat, dan melampaui batas Negara. (Kuntowijoyo, 1997:180) Memaknai budaya bukan pada tampilan-tampilan kesenian yang digelar, tetapi lebih pada seluruh hasil budi (pikiran) dan daya (kekuatan) yang dihasilkan oleh masyarakat dimana peradaban itu di bangun. Budaya itu makna bangsa yang dibangun atas dasar kesadaran idiologis dan terimplemntasi dalam tata pergaulan masyarakat berupa pola sikap tingkah laku yang ditampilkan dalam demokrasi, ekonomi, social budaya dan politik.

Keragaman budaya yang dimiliki oleh masing-masing daerah di Indonesia menjadi salah satu aset yang yang harus dipertahankan. Dari masing-masing budaya tersebut pasti memiliki cara dan pola dalam kehidupan, sehinga hal tersebut menjadi suatu kearifan lokal (local wisdom) pada masyarakat tertentu. Seharusnya hal ini yang menjadi landasan dalam pembentukan karakter pada manusia Indonesia. Setiap daerah memiliki kerifan lokal tersendiri, yang akan membantu terbentuknya karakter seseoranng akan terbentuk mulai dari lingkungan terkecil disekitar mereka. Keluarga dan lingkungan masyarakat menjadi awal dari terbentuknya karakter seseorang. Hal ini terjadi karena seseorang dengan cepat memahami dan meniru sikap yang ada pada lingkungan terdekat, sehingga menjadi suatu kebiasaan dalam kehidupan sehari-hari. (Firza, 2016)

\section{Pembahasan}




\section{Berawal dari Krisis Identitas Lokal}

Pesatnya perkembangan teknologi informasi menyebabkan pertukaran informasi dari seluruh dunia semakin mudah. Selain informasi yang bermanfaat dalam rangka transfer teknologi dan ilmu pengetahuan, seringkali kondisi ini menyebabkan terjadinya pertukaran ide, gagasan, bahkan adat kebiasaan yang seringkali justru menjadi trend baru di belahan dunia yang lain. Hal ini dapat dilihat dari cara berpakaian, jenis musik, ide dan gagasan tentang pergaulan serta gaya hidup. Berubahnya budaya, gaya hidup, bahkan identitas sebagai anak bangsa Indonesia kemudian akan menjauhkan pemuda dari nilai-nilai asli yang ada di masyarakat.

Pada kondisi inilah kemudian tranfer pengetahuan tentang kearifan lokal, pola adaptasi, dan strategi bertahan hidup yang hidup di masyarakat tidak lagi terjadi. Pada akhirnya estafet kearifan lokal yang kebanyakan tidak tertulis ini akan terputus. Kondisi ini kemudian menciptakan masyarakat yang lebih rentan dan kapasitas masyarakat yang rendah dimasa mendatang, sehingga akan meningkatkan risiko terhadap bencana. Pemuda-pemuda yang tidak lagi mengenal kearifan lokalnya, tidak akan memiliki kesiap-siagaan yang tinggi terhadap bencana. Hal ini karena mereka tidak tahu lagi tentang tanda-tanda akan terjadinya bencana, strategi bertahan hidup dalam kondisi bencana, serta pola adaptasi yang harus diterapkan untuk dapat bertahan dalam kondisi bencana. Selain itu, masyarakat yang terbentuk dari budaya yang cenderung individualis tidak akan mampu menciptakan suatu modal sosial yang kuat untuk membentuk suatu masyarakat yang tangguh bencana.

Kisah tentang kearifan lokal "Smong" di Aceh misalnya, merupakan sebuah kearifan lokal berupa seruan untuk segera menuju bukit apabila terjadi gempa bumi. Hal ini karena gempa yang terjadi dapat diikuti dengan tsunami. Kearifan ini lahir dari peristiwa tsunami Tanggal 4 Januari 1907. Lewat cerita dari mulut ke mulut, kearifan ini terus ada hingga terbukti ampuh menyelamatkan banyak nyawa pada kejadian tsunami yang terjadi hampir seratus tahun kemudian ( Tahun 2004). Namun demikian, mungkin kearifan lokal ini tidak sampai di banyak tempat di Aceh dan sekitarnya, sehingga jumlah meninggal mencapai lebih dari 173.741 orang. (https://www.republika.co.id/berita/koran/newsupdate/14/12/29/nhbv8f21-tsunami-aceh-data-korban-gempa-bumidan-tsunami-aceh) 
Kisah lain tentang ketidak pahaman terhadap kearifan lokal adalah program pemerintah Jawa Tengah yang membangun permukiman nelayan Demak yang awalnya berupa kayu menjadi tembok. Strategi adaptasi berupa menjual sebagian rumah (pintu, jendela, dinding yang terbuat dari kayu) pada saat paceklik ikan atau saat cuaca buruk di laut kemudian tidak dapat dilakukan kembali, sehingga banyak nelayan yang tidak dapat bertahan ketika terjadi paceklik ikan atau cuaca buruk, dan akhirnya terjerat hutang. Kondisi demikian menunjukkan bahwa hilangnya identitas berupa ketidak pahaman terhadap kearifan lokal dari masyarakat kita sendiri dapat menciptakan masyarakat yang sangat rentan dan akhirnya meningkatkan risiko bencana yang lebih besar.

Jepang Negara dengan kerusakan paling parah pada abad modern ini, dua bom atom meluluhlantakan dua kota di Negara matahari terbit tersebut, berbekal tekad dan keyakinan mereka bangkit bersama dengan tidak meninggalkan warisan kearifan local mereka, menjunjung tinggi adat dan agama. Contoh lain adalah Negara tetangga terdekat kita Malaysia, jaman dulu mereka belajar dari Indonesia, sekarang mereka dapat mensejajarkan diri dan mulai berani "bermanuver" mengejek kita bangsa Indonesia.

Kita yakin di setiap local wilayah Indonesia ada yang dinamakan "local wisdom" sebagai gagasan leluhur dalam menjaga tradisi berkelanjutan menghadapi tuntutan zaman. Kearifan local ini secara tak sadar mampu menjaga eksistensi tata kelola kehidupan untuk jangka ratusan dan bahkan ribuan tahun. Dan secara tak sadar pula bahwa kearifan local tersebut pasti ada sumbernya, sumber kearifan local pada dasarnya adalah kepercayaan yang dianut oleh masyarakat dimana mendiami lokasi tersebut. Jika kepercayaan bersumber dari agama samawi maka kearifan local tersebut lebih pada kecondongan terhadap filosofi ketuhanan, sedangkan kepercayaan bersumber dari hal-hal berbau dinamisme, maka "local Wisdom" yang berkembang lebih pada kegiatan yang bersifat takhayul dan kurafat.

Tatanan kearifan local yang digagas oleh para pendahulu kita, jika diperhatikan secara seksama, maka senantiasa mengajarkan kita untuk arif dalam memilih dan memilah proses kehidupan yang dijalani. Kearifan local senantiasa bersinergis dengan alam dan budaya dimana sosialita itu berkembang, begitu juga dengan local wisdom yang diajarkan oleh nenek moyang bangsa Indonesia. 
Rakyat Indonesia yang ada di daerah-daerah mulai tergerus terhadap proses globalisasi - sebuah interaksi social transkulturasi dan perkembangan modern - yang sebagian besar bangsa ini belum mampu menangkap dengan pas makna globalisasi, baik itu berbentuk demokrasi dan teori idiologi lainnya. Kita harus jujur bahwa masyarakat dan kita sendiri masih gagap dan gamang, sehingga semua bentuk globalisasi kita telan mentah-mentah dan bulat-bulat. Akhirnya perut kita sakit dan kelakuan kita akan macam-macam akibat ketidak siapan kita menghadapi ranah-ranah yang memang bukan domain kita.

Salah satu contoh nyata dapat kita ambil adalah idiologi demokrasi, proses demokrasi yang kita anut hari ini ternyata banyak membawa mudarat dari pada manfaat, terutama di daerah yang masih kental nilai-nilai kearifan lokalnya. Gara-gara demokrasi berjalan persaudaraan runtuh, timbul permusuhan, saling curiga dan bahkan sesama saudara tak saling tegur sapa, gara-gara beda pilihan. Artinya demokrasi liberal yang kita jalankan hari ini sangat tidak sesuai dengan demokrasi yang diajarkan dalam konteks kearifan local. Maka akan timbul tanda Tanya dimana kearifan local yang selama ini menjadi sendi-sendi kehidupan ?. kearifan local jika ditelisik lebih jauh itu berawal dari budaya yang diajarkan oleh nenek moyang kita yang bertumpu pada kecerdasan moral.

Ajaran leluhur tentang kecerdasan moral adalah kemampuan memahami yang benar dan yang salah. Artinya, memiliki keyakinan etika yang kuat dan bertindak berdasarkan keyakinan tersebut, sehingga orang bersikap benar dan terhormat. Kecerdasan moral ini mencakup karakter-karakter utama, seperti kemampuan untuk memahami penderitaan orang lain dan tidak bertindak jahat; mampu mengendalikan dorongan dan menunda pemuasan; mendengarkan dari berbagai pihak sebelum memberikan penilaian; menerima dan menghargai perbedaan; bisa memahami pilihan yang tidak etis; dapat berempati; memperjuangkan keadilan dan menunjukan kasih sayang serta rasa hormat terhadap orang lain. (Michele Borba, 2008: 4)

\section{Menggagas Civic Education Berbasis Kearifan Lokal}

Banyaknya nilai-nilai kearifan local yang berguna namun "hilang" harus kita restart. Ini gagasan, dengan berargumentasi 
bahwa kearifan local sampai hari ini mampu menopang pandanganpandangan kehidupan ke-modern-an. Ada keunggulan tersendiri dan menjadi "icon" bahwa leluhur kitapun sudah berpandangan maju menyikapi perkembangan zaman.

Kalau kita gali secara mendalam, ternyata warisan-warisan terdahulu bukan an sich etika, ada ajaran lain tentang hak dan kewajiban warga Negara, tentang hukum, tentang budaya dan lain sebagainya. Bagaimana mengembalikan tatanan pemerintahan yang handal dan di segani, di kearifan local bisa memberikan jawaban.

Kembalikan pendidikan demokrasi kita kepada penyesuaian demokrasi yang berkembang di daerah, adalah tidak demokrasi jika gagasan itu diseragamkan menjadi sama, pada hal daerah-daerah berbeda adat istiadatnya. Dan tidaklah fair jika hanya berlandaskan demokrasi lalu dapat "mengacak-acak" kekayaan yang di wariskan nenek moyang. Kenapa kearifan lokal menjadi penting dalam pendidikan warga? Karena pada dasarnya kearifan lokal merupakan kebenaran yang telah mentradisi atau ajeg dalam suatu daerah. Kearifan lokal merupakan perpaduan antara nilai-nilai suci firman Tuhan dan berbagai nilai kebaikan yang ada. Atau dalam pepatah melayu mengatakan “adat bersendikan syara', syara' bersendikan kitabullah". Kearifan lokal terbentuk sebagai keunggulan budaya masyarakat setempat maupun kondisi geografis dalam arti luas.

Kearifan lokal merupakan produk budaya masa lalu yang patut secara terus-menerus dijadikan pegangan hidup. Meskipun bernilai lokal tetapi nilai yang terkandung di dalamnya dianggap sangat universal. Sehingga dengan mengintegrasikan kearifan lokal dalam desain pembentukan karakter anak, secara tidak langsung anak akan mendapatkan gambaran yang utuh atas identitas dirinya sebagai individu, serta identitas dirinya sebagai anggota masyarakat yang terikat dengan budaya yang ungul dan telah lama diugemi/dipegang para pendahulunya. Kearifan lokal merupakan pengetahuan yang eksplisit yang muncul dari periode panjang, yang berevolusi bersamasama masyarakat dan lingkungannya dalam sistem lokal yang sudah dialami bersama-sama. Proses evolusi yang begitu panjang dan melekat dalam masyarakat, dapat menjadikan kearifan lokal sebagai sumber energi potensial dari sistem pengetahuan kolektif masyarakat, untuk hidup bersama secara dinamis dan damai.

Kearifan lokal yang digali, dipoles, dikemas, dipelihara dan dilaksanakan dengan baik bisa berfungsi sebagai alternatif pedoman 
hidup manusia. Nilai-nilai itu dapat digunakan untuk menyaring nilainilai baru atau asing, agar tidak bertentangan dengan kepribadian bangsa dan menjaga keharmonisan hubungan manusia dengan Sang Khalik, alam sekitar dan sesamanya. Selain itu, kearifan lokal dapat menjadi benteng kokoh menanggapi modernitas dengan tidak kehilangan nilai-nilai tradisi lokal yang telah mengakar dalam sebuah komunitas masyarakat atau daerah.

Oleh karena itu sudah menjadi kewajiban seluruh steakholders pendidikan untuk merumuskan sebuah cetak biru "blue print" yang original mengenai falsafah pendidikan, terutama didaerah-daerah dikala seluruh tatanan kehidupan mengarah pada fenomena tercerabutnya akar tradisi nilai social, maka dalam rangka menghadapi tantangan "kosmos brutal” secara etika, kearifan local menjadi alternatif pilihan. Kearifan local sudah demikian teruji selama ratusan dan bahkan ribuan tahun dalam tatanan yang penuh dengan harmonisasi antara manusia dengan manusia maupun dengan alam.

\section{Mempersiapkan Generasi Penerus Cinta Kearifan Lokal}

Generasi penerus beridentitas hendaknya disiapkan sedari kecil. Penanaman nila-inilai kebangsaan, kearifan lokal dan rasa cinta tanah air hendaknya dilakukan dengan memasukkannya di dalam kurikulum. Masing-masing wilayah memiliki kearifan lokal, maka hendaknya kurikulum juga disiapkan sampai pada tingkat lokal. Tentunya diperlukan kerja ekstra dari guru di tingkat sekolah dasar dan sekolah menenngah untuk menyiapkan hal tersebut. Selain menyiapkan generasi muda beridentitas melalui kurikulum sekolah, pemerintah hendaknya juga memberikan kesempatan yang luas terhadap pemuda untuk mengakses pendidikan dan pekerjaan. Kondisi ini penting agar generasi muda dapat menggunakan masa mudanya untuk suatu aktifitas yang positif.

Dengan demikian mereka tidak akan cukup waktu untuk melakukan hal-hal yang negatif. Upaya memaksimalkan peran generasi penerus dalam pembangunan negara dapat dilakukan dengan memfasilitasi organisasi-organisasi kepemudaan yang positif termasuk memfasilitasi organisasi kampus. Hal ini penting sebagai ajang para generasi penerus untuk mengejawantahkan ide-idenya, sekaligus sebagai sarana untuk pembelajaran menjadi pemimpin masa depan. Dengan adanya generasi penerus yang beridentitas dan 
berakar budaya bangsa diharapkan estafet kearifan lokal dapat terus berjalan, tentunya dengan berbagai penyempurnaan dengan memanfaatkan teknologi tanpa kehilangan nilai-nilai asalnya.

\section{Simpulan}

Secara peraturan pemerintah Negara Republik Indonesia telah menetapkan bahwa Undang-Undang dalam system Pendidikan Nasional Nomor 20 Tahun 2003 telah menyebutkan dalam pasal 1 ayat 1 bahwa Pendidikan adalah usaha dan terencana untuk mewujudkan suasana belajar dan proses pembelajaran, agar peserta didik secara aktif mengembangkan potensinya sendiri untuk memiliki kekuatan spiritual keagamaan, pengendalian diri, kepribadian, kecerdasan, akhlaq mulia serta ketrampilan yang perlukan dirinya, masyarakat, bangsa dan Negara.

Di jelaskan lebih lanjut dalam bab umum ayat 16 bahwa Pendidikan berbasis masyarakat adalah penyelenggaraan pendidikan berdasarkan kekhasan agama, sosial, budaya, aspirasi, dan potensi masyarakat sebagai perwujudan pendidikan dari, oleh, dan untuk masyarakat. Oleh karena itu krisis-krisis yang menyebabkan nilai-nilai identitas bangsa mulai pudar adalah ketika amanah Pancasila, Undang-Undang Dasar 1945 dan Undang-Undang yang mengatur tentang pendidikan tidak dijalankan secara baik.

Perlu keseimbangan dalam mengatur proses kemajuan sebuah bangsa, kemajuan tidak semata hanya bertumpu pada sector ekonomi tetapi budaya, dan karakter (etos) kebangsaan yang berakar dari nilai leluhur itu hilang, maka bangsa itu akan menjadi kerdil dan menjadi bangsa yang tak punya identitas yang jelas.

Oleh karena itu secara umum pembangunan suatu Negara adalah bagaimana membangun secara komprehensif (segala bidang) tetap mengacu atau berlandaskan kearifan local bangsa, baik demokrasi, ekonomi, budaya dan social lainnya. Karena ini jaminan agar bangsa tidak kehilangan jati dirinya. 


\section{DAFTAR PUSTAKA}

Agustian, Ari Ginandjar.2001. ESQ : Rahasia Sukses Membangun Kecerdasan Emosi dan Spiritual Berdasarkan 6 Rukun Iman dan 5 Rukun Islam, Jakarta: Arga.

Aiken, Henry.2000. Abad Ideologi, terj. Sigit Djatmiko.Yogyakarta: Bentang Budaya.

Borba, Michele. 2008. Membangun Kecerdasan Moral. Jakarta: PT. Gramedia Pustaka Utama.

Capra, Fritjof. 1998. Titik Balik Peradaban Sains, Masyarakat dan Kebangkitan Budaya. Yogyakarta: Yayasan Bentang Budaya.

Dahler, Franz dan Eka Budianta.2000.Pijar Peradaban Manusia: Denyut Harapan Evolusi. Jakarta: Kanisius.

Firza,. 2016. Local Wisdom Sebagai Dasar Pembentukan Karakter (Prosiding Seminar Nasional Feforming Pedagogy https://www.republika.co.id/berita/koran/newsupdate/14/12/29/nhbv8f21-tsunami-aceh-data-korban-gempabumi-dan-tsunami-aceh

Fromm, Erich.1988. To Have Or To Be? New York Hagerstown, San Fransisco, London.

Hamidi, Jazim. dan Mustafa Lutfi. 2010. Civic Education Antara Realitas Politik dan Implementasi Hukumnya. Jakarta: PT. Gramedia Utama.

Kuntowijoyo. 1997. Identitas Politik Umat Islam. Bandung : Mizan. Latif, Yudi. 2011. Negara Paripurna, Historisitas, Rasionalitas, dan Aktualitas Pancasila. Jakarta: PT. Gramedia Pustaka Utama.

Listyarti, Retno. 2012. Pendidikan Karakter Dalam Metode Aktif, Inovatif dan Kreatif. Jakarta: Erlangga. 
Madjid, Nurcholish. 2000. Kehampaan Spiritual Masyarakat Modern: Respon dan Transformasi Nilai-Nilai Islam Menuju Masyarakat Madani. Jakarta: Media Cita.

Muniron.1999. Pandangan Al-Ghazali Tentang Ijtihad dan Hulul, Jurnal pemikiran Islam paramadina, Volume I, Nomor 2.

Muthahari, Murtadha.1998. Fitrah. Terj. Jakarta: Lentera.

Nottingham, Elizabeth. 1985. Agama dan Masyarakat: Suatu Pengantar Sosiologi Agama, terj. Abdul Muis Naharong. Jakarta: Rajawali.

Tohari, Amin Dkk. 2011. Dinamika Konflik dan Kekerasan Di Indonesia. Jakarta: Tim Penulis Institut Titian Perdamaian. 